\section{Oncology}

Oncology 2009;77:162-171

DOI: $\underline{10.1159 / 000231886}$
Received: October 2, 2008

Accepted after revision: February 9, 2009

Published online: July 28, 2009

\title{
Clinical Profile, Etiology and Therapeutic Outcome in 324 Hepatocellular Carcinoma Patients at a Tertiary Care Center in India
}

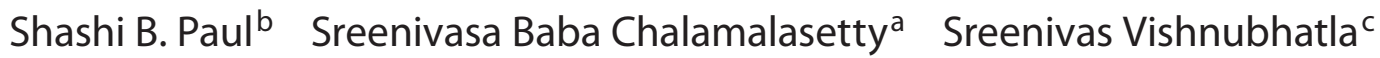 \\ Kaushal Madan ${ }^{a}$ Shivanand R. Gamanagatti ${ }^{b}$ Yogesh Batra ${ }^{a}$ \\ Siddhartha D. Guptad Subrat K. Pandad Subrat K. Acharya ${ }^{a}$ \\ Departments of a Gastroenterology, ${ }^{b}$ Radiodiagnosis, ${ }^{\mathrm{c} B i o s t a t i s t i c s}$ and ${ }^{\mathrm{d}}$ Pathology, All India Institute of \\ Medical Sciences, New Delhi, India
}

\section{Key Words}

Hepatocellular carcinoma · India · Serum $\alpha$-fetoprotein .

Etiology $\cdot$ Staging $\cdot$ Treatment

\begin{abstract}
Objective: To study the profile and outcome of therapy for hepatocellular carcinoma (HCC) in India. Methods: Data analysis of HCC patients enrolled in liver clinic between 1990 and 2005. Results: We registered 324 HCC patients [males 284 (88\%), mean age $52.4 \pm 13.1$ years]. The etiology of HCC was: hepatitis $B$ virus $165(51 \%)$, hepatitis C virus $38(12 \%)$, alcohol $20(6 \%)$, combined 31 (10\%) and unknown $70(21 \%)$. Serum $\alpha$-fetoprotein was $>400 \mathrm{ng}$ in $36 \%$, portal vein invasion was seen in $40 \%$ and distant metastases in $13 \%$. Therapy was offered to $141(43.5 \%)$ patients, but survival data was available in only 130 (93\%) of them. Treatment given and median survival time was as follows: surgical resection, 19 months $(n=14)$; transarterial chemoembolization, 11 months $(n=23)$; transarterial rhenium therapy, 26 months $(n=7)$; radiofrequency ablation, 24 months $(n=4)$; acetic acid ablation, 13 months ( $n=17)$; oral chemotherapy, 26 months $(n=33)$, and combination therapy, 26 months $(n=32)$. Vascular invasion, Okuda staging and therapy were independent factors associated with survival. Treated patients had longer median survival compared to untreated ones (16 months vs. 7 months, $p<0.05)$. Conclusions: Hepatitis B infection is the predomi-
\end{abstract}

\section{KARGER}

Fax +41613061234 E-Mail karger@karger.ch www.karger.com (c) 2009 S. Karger AG, Basel

$0030-2414 / 09 / 0774-0162 \$ 26.00 / 0$

Accessible online at:

www.karger.com/ocl nant cause of HCC in India. Serum $\alpha$-fetoprotein was diagnostic in only one third of our patients. Most patients present late, when curative therapies are not possible. Treated patients had better survival than untreated ones.

Copyright $\odot 2009$ S. Karger AG, Basel

\section{Introduction}

The burden of hepatocellular carcinoma (HCC) is increasing and at present HCC is ranked as the fifth most common cancer worldwide [1]. The incidence of HCC varies widely with the geographic location as risk factors for the development are variably distributed across continents and within countries. Age-adjusted incidence rates for liver cancer in developing countries are 2- to 3fold higher than in the developed countries [2]. Approximately $80 \%$ of liver cancers occur in Asia and Africa [3].

Existence of chronic liver disease, especially cirrhosis, represents a potential risk for the development of HCC. Cirrhosis, mainly caused by hepatitis B virus (HBV) and hepatitis $\mathrm{C}$ virus (HCV), constitutes a major risk factor for HCC, with a 5-year cumulative incidence ranging from $15-20 \%$ [4]. While HCV is the most common cause of HCC in the USA and Japan, HBV appears to be the most important etiological agent for HCC in southeast Asian countries, including China and Taiwan [5].

Dr. S.K. Acharya

Department of Gastroenterology

All India Institute of Medical Sciences

New Delhi 110029 (India)

Tel. +91 112659 4934, Fax +91 112658 8663, E-Mail subratacharya2004@yahoo.com 
India lies in the intermediate endemic zone of HBV infection with hepatitis B surface antigen (HBsAg) carrier frequency of $2-4 \%$ in the community [6]. HBV infection is the leading cause of chronic liver disease in India and is responsible for $35-60 \%$ of chronic liver disease and $60-80 \%$ of HCC [5]. Earlier studies from India suggest that the odds ratio of HBsAg positivity among HCC patients is one of the highest in the world [7]. About 15 million people are infected by HCV and the population prevalence of anti-HCV antibodies is about 1\% [8]. Thus, there is a large pool of people who are at risk of developing chronic liver disease and, therefore, HCC. Post-mortem studies from India show a prevalence of HCC varying from 0.2 to $1.6 \%$ [9]. A recently published prospective cohort study has revealed the incidence of HCC among Indian patients of cirrhosis as $1.6 \%$ per year [10].

There is a paucity of data pertaining to the clinical profile, etiology, outcome of therapy and survival of HCC patients in India. Such information in India may be important to formulate guidelines for early detection and treatment of HCC in this country. This study was designed to provide the clinical features, underlying risk factors, tumor characteristics and outcomes of therapy in HCC patients from India.

\section{Methods}

Patients of HCC presenting to the liver clinic of the All India Institute of Medical Sciences, a tertiary care center in India, between 1990 and 2005, were included in the study.

\section{Study Design}

Patients included were divided into 2 groups: group I included those who presented between 1990 and 2000, and group II contained those who presented between 2001 and 2005. For group I, the data were collected retrospectively from the case records, and for group II, data were accumulated by prospective follow-up from 2001 onwards. During the later period (2001-2005), screening services for HCC were started at the liver center of our institute.

\section{Patient Evaluation}

Clinical evaluation included detailed history and physical examination. Investigations included complete blood count, liver function tests and viral markers for HBV and HCV. Upper gastrointestinal endoscopy was done in each to detect the presence of esophageal varices. Serum $\alpha$-fetoprotein (AFP) was estimated using a particle enzyme immunoassay (Axsym System; Abbott Laboratories, Abbott Park, Ill., USA; normal range $<20$ ng/ml).

The hepatitis viral markers, including HBsAg (Organon Teknika, Boxtel, The Netherlands), anti-HCV (Xcyton, Bangalore, India), total anti-HBc and $\mathrm{HBeAg}$ (Bio-Rad, MonoLISA, France) were tested using commercial ELISA [11]. HBV DNA and
HCV RNA were first detected using qualitative PCR [12-14] and if they were positive, they were quantitated by in-house competitive PCR (CT-PCR) described earlier [14, 15]. The sensitivity of qualitative PCR for HBV DNA was 100 copies/ml, for HCV RNA 500 copies/ml $[12,13]$ and for CT-PCR it was $10^{2}$ copies/ml [14, 15]. These tests were done at initial presentation and every 3 months thereafter in patients treated with antiviral drugs. Among patients positive for $\mathrm{HBV}$ infection, genotyping was performed in a random sample of HBV-induced HCC.

Radiological work-up comprised of an abdominal ultrasonogram and contrast-enhanced CT abdomen for patients of group I. For group II patients, a triple-phase CT (TPCT) of the liver was done at the time of enrolment. Contrast-enhanced multiphasic MRI was also done in this group when required for the diagnosis of HCC.

Diagnosis of cirrhosis was made on the basis of clinical, biochemical and endoscopic findings. Liver biopsy was done wherever necessary. HBV cirrhosis was diagnosed when detectable $\mathrm{HBs}$ Ag in serum was present. HCV cirrhosis was diagnosed when detectable anti-HCV, HCV RNA or both was present in serum.

Alcoholic cirrhosis was labeled when the patient had a history of alcohol consumption of $\geq 80 \mathrm{~g} /$ day for more than 5 years. Severity of cirrhosis was graded based on the Child-Pugh classification [16].

Diagnostic criteria for HCC in group I were any of the following: AFP $>300 \mathrm{ng} / \mathrm{ml}$ or hypervascular liver mass on contrast-enhanced CT abdomen or fine needle aspiration cytology (FNAC). For group II, the modified European Association for Study of Liver criteria [4] were followed. This consisted of either FNAC or any 2 of the following: AFP $>300 \mathrm{ng} / \mathrm{ml}$ or arterialization of the mass on TPCT or MRI. MRI was performed at times to document arterial enhancement of lesion in patients who had arterial enhancement with TPCT, but did not have requisite raised AFP values and who had equivocal FNAC. Therefore, arterial enhancement on 2 imaging modalities could be achieved in these cases, satisfying the European Association criteria.

Staging of HCC was done according to the Barcelona Clinic Liver Cancer (BCLC) staging classification [17], retrospectively for group I and prospectively for group II.

\section{Treatment}

Various types of treatment therapies available at our center, were given keeping into account factors like stage of the disease, underlying presence of cirrhosis and its severity. Therefore, findings on CT and TPCT indicating tumor burden, portal vein involvement, presence of extra-hepatic disease or distant metastasis were recorded. Child's score and PST score of the patient was also noted and the treatment was then finally decided.

\section{Locoregional Therapies}

BCLC A stage patients were offered surgery if their liver function was good with no clinically relevant portal hypertension. If not, then surgery could not be undertaken, and instead local ablative therapies were performed. These local ablative therapies were radiofrequency ablation (RFA) or percutaneous acetic acid injection (PAI) and were undertaken at our center from 2001 onwards. RFA and PAI were done in those patients who had HCC $\leq 5 \mathrm{~cm}$ and $\leq 5$ in number. The RFA technique being expensive, this treatment was offered only to those who could bear the cost of the needle electrode, failing which, PAI was undertaken as the thera- 
Fig. 1. Radio frequency ablation. a Arterial phase of TPCT showing a solitary, peripherally located, enhancing HCC (arrow) in the liver. RFA was performed. b TPCT performed at 4 weeks shows the same mass as uniformly hypodense, larger than the pretreatment size and with no enhancing viable tissue, suggesting complete ablation.

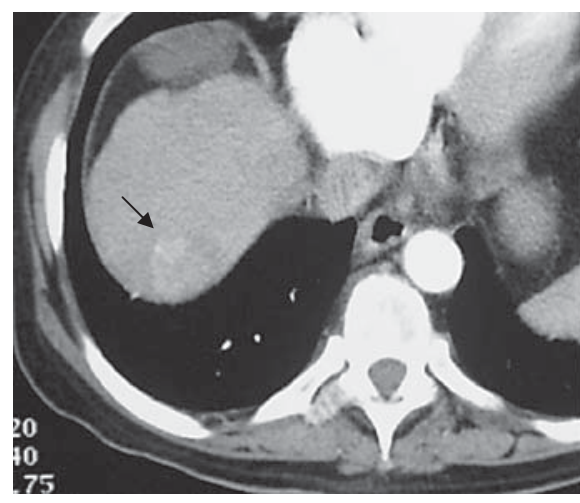

a
Before RFA

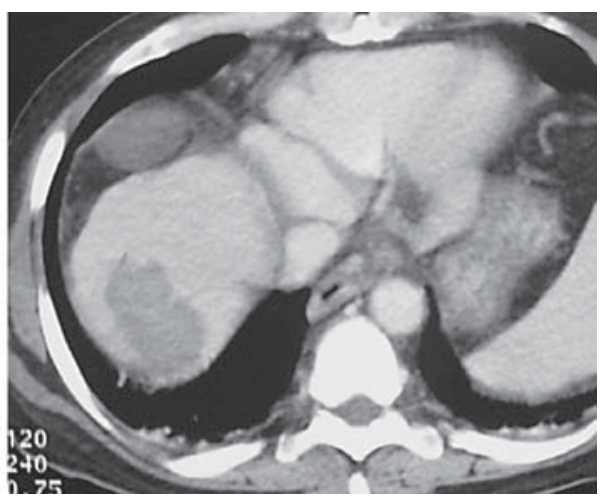

b
After RFA (4 weeks)

Fig. 2. Percutaneous acetic acid injection (PAI). a Arterial phase of TPCT showing an enhancing, well defined HCC (arrow) in the left lobe of liver. After subjecting to PAI, TPCT done at 4 weeks (b) shows the same mass as uniformly hypodense with no enhancing viable tissue suggesting complete ablation.

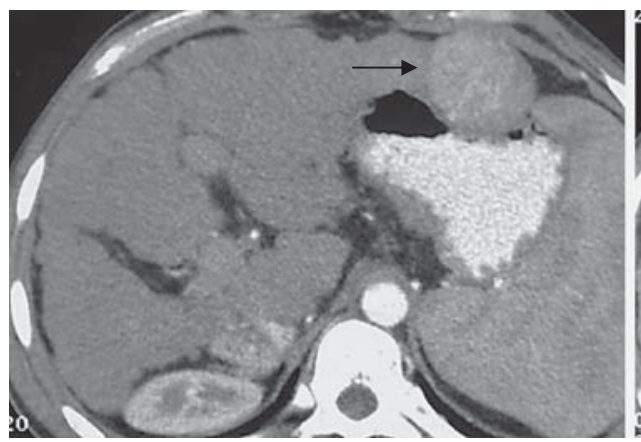

a
Before PAI

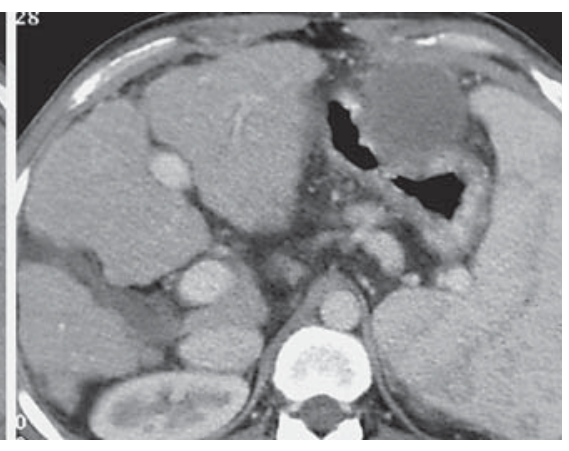

b
After PAI (4 weeks) peutic option. Patients having tumor close to the surface of liver without a rim of normal liver tissue around the tumor margin, near the diaphragm, major hepatic vessels and gall bladder were excluded from ablative therapy and the regional therapy of transarterial chemoembolization (TACE) was undertaken to avoid procedure-related complications. Other considerations were normal coagulation profile and absence of associated co-morbid illnesses.

\section{Radiofrequency Ablation}

The procedure was performed using a cool-tip RF system (Radionics, Burlington, Mass., USA) with continuous ice cold perfusion system. The procedure was done under local anesthesia and sedation. A single or cluster electrode (depending upon the size of the mass) was inserted into the mass using ultrasound guidance. The needle tract was cauterized by withdrawing the electrode while still hot. End temperature $>60^{\circ} \mathrm{C}$ was achieved at the end of each session (fig. 1). Platelet-rich plasma was transfused if platelet count was $<50,000 / \mu l$.

\section{Percutaneous Acetic Acid Injection}

Under local anesthesia using ultrasound guidance, $40 \%$ glacial acetic acid was injected into the mass through the percutaneous route using a $22 \mathrm{G}$ spinal needle. Multiple sessions of PAI were performed and 1.5-2 $\mathrm{ml}$ was injected in 1 session per week (total dose not exceeding 3 times the diameter of the mass; fig. 2). To minimize post-procedural pain, injection bupivacaine (Sensorcaine) was administered at a dose of 4-5 $\mathrm{ml}$ through the same needle into the tumor, needle track and the liver capsule while gently withdrawing the needle.

Transarterial Chemoembolization

Patients of BCLC stages B and C with patent main portal vein, with or without segmental or lobar portal vein invasion and who did not have extrahepatic disease were offered either transarterial rhenium therapy (TART) or TACE. The few cases of BCLC stage A which were unsuitable for ablation or surgery (not fulfilling the inclusion criteria for ablation) were also treated with TACE. The TACE procedure was carried out by preparing a stable drug mixture of doxorubicin $50 \mathrm{mg}$ and cisplatin $100 \mathrm{mg}$ in combination with $10-15 \mathrm{ml}$ of ionic contrast media and $10-20 \mathrm{ml}$ of lipiodol by continuously agitating the mixture. Superselective catheterization of the hepatic artery supplying the mass was performed through the femoral artery puncture in the upper thigh. Gelfoam particles were injected subsequent to institution of intraarterial chemotherapy for embolization to occlude the artery supplying the mass (fig. 3a, b).

Transarterial Rhenium Therapy

A stable lipophilic chelate with rhenium, called ${ }^{188}$ Re HDDlipiodol, was prepared and $185 \mathrm{MBq}(5 \mu \mathrm{Ci})$ was initially injected through the $4 / 5 \mathrm{~F}$ preshaped catheter in the hepatic artery branch- 
Fig. 3. TACE for local recurrence of HCC following surgery. A small, exophytic, local recurrence following surgery in segment 8 of liver on arterial phase MRI. a TACE was performed and follow up after TACE with arterial dominant CT. b Lipiodol completely covering the mass and the adjoining hepatic parenchyma with no enhancing residual tissue. Multiple para-esophageal collaterals are also seen.
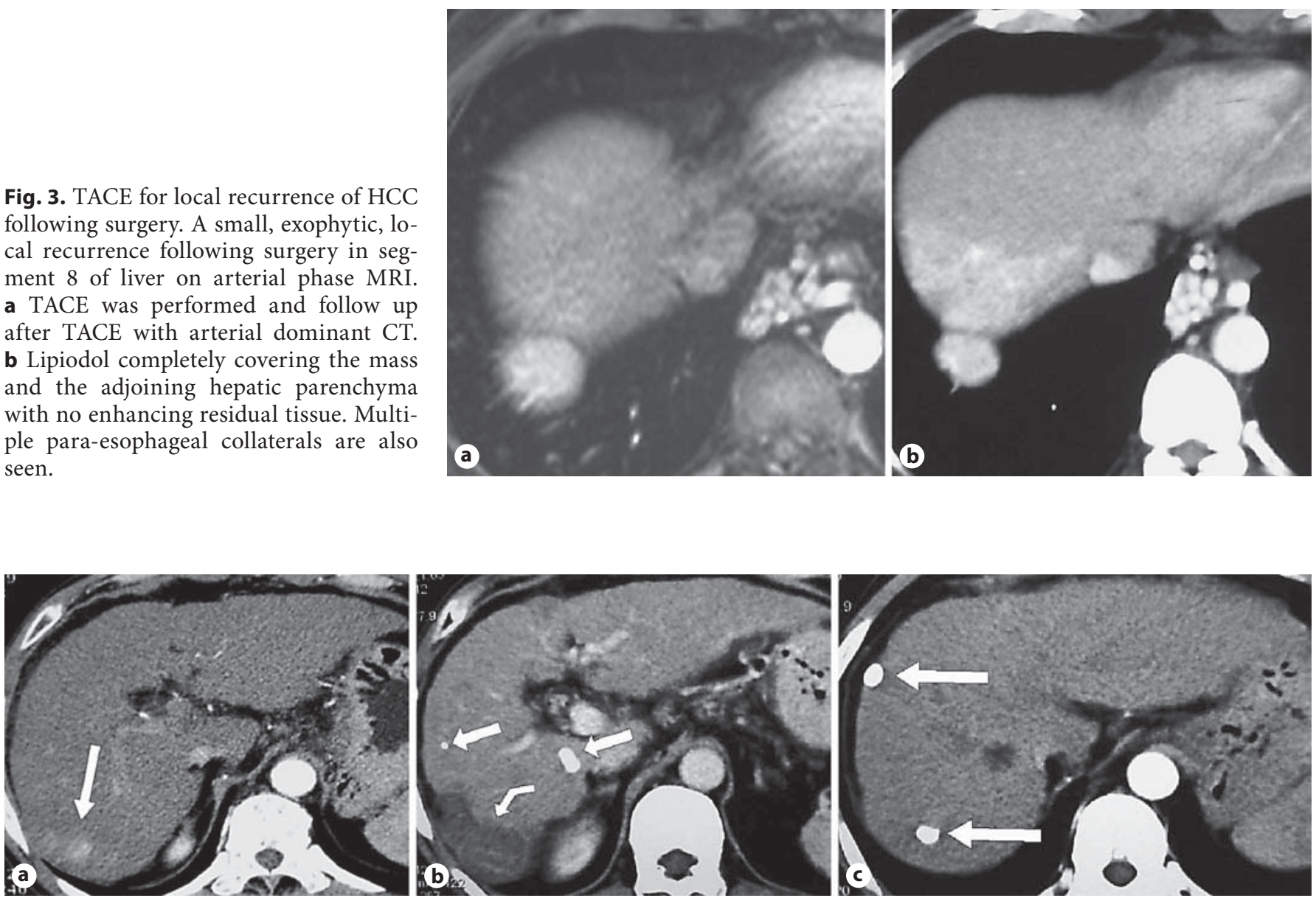

Fig. 4. Combination modality (RFA followed by TACE). A small, solitary enhancing mass in segment 7 of liver on arterial phase CT (a), treated with RFA. At 18 months, multiple fresh lesions along with recurrence at the margin of the defect were noted and TACE was performed. Post-TACE CTs $(\mathbf{b}, \mathbf{c})$ show lipiodol-covered lesions. Straight arrows $=$ fresh lesions; curved arrow $=$ recurrence.

es after performing the femoral artery puncture in the upper thigh. Subsequently, whole-body imaging was performed under the gamma camera, after infusing the standard dose of Re-188lipiodol $(100 \mu \mathrm{Ci})$ mixture via the femoral artery catheter. The radiation-absorbed dose was calculated for the lungs, whole liver and tumor only. This calculated dose was then injected through the catheter in the hepatic artery feeding the tumor.

\section{Combination Therapy}

A combination of different treatment modalities was used in some patients. The modalities used were RFA, TACE and PAI (fig. 4). This mode of therapy was chosen for a few of the BCLC stage A patients who changed to BCLC stage $\mathrm{B} / \mathrm{C}$ on follow-up after therapy. Some patients of BCLC stage B/C who failed to respond favorably following TACE/TART were also subjected to combination therapy with ablation (either RFA or PAI) for the poorly responding index tumor.

\section{Oral Chemotherapy}

Two categories of patients of BCLC stage $\mathrm{D}$ were given oral chemotherapy: (1) advanced HCC patients having Child's A/B cirrhosis, with portal vein involvement and extrahepatic spread, Performance Status score 0-2, and (2) terminal stage HCC with Child's C cirrhosis, PST score $>2$ (therapy offered to those who could afford it while others were offered only symptomatic treatment).

Systemic oral chemotherapy with 5-fluorouracil, long-acting somatostatin or a combination of anti-angiogenic drugs and thalidomide along with capecitabine was given.

Adjuvant Therapy

All patients with cirrhosis who had evidence of high-risk varices on endoscopy underwent primary prophylaxis with endoscopic variceal banding. Patients who had HBV-related HCC along with markers of active viral replication were given antiviral treatment with oral lamivudine $100 \mathrm{mg}$ daily. The other complications of chronic liver disease and HCC were managed with conventional treatment. 


\section{Follow-Up}

All treated patients were followed up by detailed clinical examination, serum AFP and TPCT at 1, 3 and 6 months to assess the response. Thereafter, TPCT was done once a year. If CT showed residual or recurrent disease, the therapy allotted (TACE/ $\mathrm{RFA} / \mathrm{PAI}$ ) was repeated provided the patient was found clinically fit with a Child's status of A/B. In certain situations where CT/ TPCT showed no evidence of recurrence or fresh lesions following treatment, but the patient had rising serum AFP level, repeat TACE was undertaken. If there was progression of disease on follow-up imaging, then, depending upon the BCLC stage of the disease, other available treatment options were also considered. Hence, in patients treated with either TACE or RFA/PAI, single or multiple sessions were undertaken depending upon their response to therapy.

\section{Statistical Analysis}

Data analyses were performed using Stata (version 9.0). Continuous data were expressed as mean (SD) or median (range) and categorical data as proportions. Data for median survival were analyzed using Kaplan-Meier analysis, and survival difference among various groups was tested using the log-rank test. Cox regression analysis was used for assessing factors associated with survival. A p value $<0.05$ was considered significant.

\section{Results}

A total of 324 patients with HCC were registered in the liver clinic (50 in group I and 274 in group II).

\section{Clinical Profile and Liver Function Status}

The mean age at presentation was $52.4 \pm 13.1$ years (range 18-92 years) and 284 (88\%) of them were males. Abdominal pain in the right upper quadrant was the predominant symptom in $53 \%$ of the patients (table 1 ). Recent onset ascites was the main complaint in $13 \%$, while weight loss was present in $9 \%$ (table 1). Patients with HCC who were asymptomatic were diagnosed to have the disease during routine ultrasonographic evaluation for vague abdominal complaints. There was a past history suggestive of acute hepatitis in 34 (11\%) and chronic hepatitis in $26(8 \%)$ patients. History of significant intake of alcohol was present in $44(14 \%)$ with a mean intake of 86 g/day and median duration of 17.5 years (range $0-40$ ). The biochemical markers, Child's class and presence of esophageal varices are shown in table 2. Esophagoscopy revealed presence of esophageal varices in 134 (58\%) patients.

\section{Etiology}

A significant proportion of our patients (316/324, 97.5\%) had underlying cirrhosis.
Table 1. Demographic profile and clinical features of HCC patients $(\mathrm{n}=324)$

\begin{tabular}{|c|c|c|}
\hline Characteristic & Frequency & $\%$ \\
\hline \multicolumn{3}{|l|}{ Age, years } \\
\hline Mean \pm SD & $52.4 \pm 13.1$ & \\
\hline Range & $16-92$ & \\
\hline \multicolumn{3}{|l|}{ Sex, n } \\
\hline Male & 284 & 88.0 \\
\hline Female & 40 & 12.0 \\
\hline \multicolumn{3}{|l|}{ Predominant symptom, $\mathrm{n}$} \\
\hline Pain & 174 & 53.2 \\
\hline Ascites & 41 & 12.7 \\
\hline Weight loss & 28 & 8.9 \\
\hline Fever & 20 & 6.3 \\
\hline Lethargy & 15 & 4.6 \\
\hline Lump & 12 & 3.8 \\
\hline Asymptomatic & 34 & 10.5 \\
\hline \multicolumn{3}{|l|}{ History of } \\
\hline Acute hepatitis & 34 & 11.0 \\
\hline Chronic hepatitis & 26 & 8.0 \\
\hline Blood transfusion & 23 & 7.0 \\
\hline \multicolumn{3}{|l|}{ Significant alcohol consumption } \\
\hline Consuming $\geq 80 \mathrm{~g} /$ day, $\mathrm{n}$ & 45 & 14.0 \\
\hline Quantity, g/day & $86 \pm 53$ & \\
\hline Median duration (range), years & $17.5(0-40)$ & \\
\hline Smokers, n & 32 & 10.0 \\
\hline
\end{tabular}

Table 2. Liver function tests, Child's class and endoscopic examination $(\mathrm{n}=324)$

\begin{tabular}{lc}
\hline Serum bilirubin, mg/dl & $1.3(0.2-26.3)$ \\
Serum albumin, g/dl & $3.5(1.6-9.8)$ \\
AST, U/l & $87.5(15-559)$ \\
ALT, U/l & $58(7-507)$ \\
SAP, U/l & $330.5(10-2,720)$ \\
Child's class & \\
$\quad$ A & $165(51)$ \\
B & $110(34)$ \\
C & $49(15)$ \\
Grade of varices $(\mathrm{n}=232)$ & \\
No varices & $98(42.2)$ \\
1 & $11(4.7)$ \\
2 & $75(32.3)$ \\
3 & $38(16.4)$ \\
4 & $10(3.1)$
\end{tabular}

Data are median (range) or $\mathrm{n}(\%)$ as appropriate. 
Table 3. Etiological factors associated with HCC $(\mathrm{n}=324)$

\begin{tabular}{lc}
\hline Etiology & $\mathrm{n}(\%)$ \\
\hline HBV & $165(50.9)$ \\
HCV & $38(11.7)$ \\
Alcohol & $20(6.1)$ \\
HBV + alcohol & $17(5.2)$ \\
HBV + HCV & $7(2.2)$ \\
HCV + alcohol & $4(1.2)$ \\
HBV + HCV + alcohol & $3(0.9)$ \\
Unknown & $70(21.6)$ \\
\hline
\end{tabular}

Table 4. Tumor characteristics

\begin{tabular}{lc}
\hline Characteristic & $\mathrm{n}(\%)$ \\
\hline AFP, $\mathrm{ng} / \mathrm{ml}(\mathrm{n}=271)$ & $77(29)$ \\
$\quad<10$ & $93(35)$ \\
$\quad 10-400$ & $101(36)$ \\
$>400$ & \\
Size, $\mathrm{cm}(\mathrm{n}=313)$ & $48(16)$ \\
$<3$ & $54(18)$ \\
$>3-5$ & $211(67)$ \\
$>5$ & $215(69)$ \\
Number of lesions $(\mathrm{n}=313)$ & $48(15)$ \\
Solitary & $15(5)$ \\
$2-3$ & $35(11)$ \\
$4-5$ & $129(40)$ \\
$>5$ & $41(12.7)$ \\
Portal vein thrombosis & \\
Distant metastasis & $100(31.9)$ \\
Okuda staging $(\mathrm{n}=313)$ & $169(54)$ \\
1 & $44(14.1)$ \\
2 & \\
3 & $60(20.5)$ \\
BCLC staging $(\mathrm{n}=292)$ & $101(34.6)$ \\
A & $80(27.4)$ \\
B & $51(17.5)$ \\
C & \\
D & \\
\hline
\end{tabular}

BCLC $=$ Barcelona Clinic Liver Cancer Staging.

HBV infection was the most common etiological factor and was detected in 192 (59\%) patients. Of these, HBV alone was the causative agent in 165 (51\%), and in the remaining patients, association with $\mathrm{HCV}$ and alcohol was present (table 3).

Of those patients who were HBeAg negative $(\mathrm{n}=145)$, HBV DNA was positive in 18 (12\%), qualifying as 'e mutants'. A HBV genotype analysis of 38 patients chosen at

Hepatocellular Carcinoma in India
Table 5. Modalities of therapy and survival

\begin{tabular}{lccc}
\hline \multirow{2}{*}{ Treatment } & Patients, n (\%) & Survival & \\
\cline { 3 - 4 } & & median & range \\
\hline Surgical resection & $14(10.7)$ & 19 & $1-28$ \\
RFA & $4(3.0)$ & 24 & $2-30$ \\
PAI & $17(13.1)$ & 13 & $1-51$ \\
TACE & $23(17.7)$ & 11 & $1-41$ \\
TART & $7(5.4)$ & 26 & $1-32$ \\
Oral chemotherapy & $33(25.3)$ & 5 & $1-16$ \\
Combination therapy & $32(24.6)$ & 26 & $1-58$ \\
\hline Total treated & 130 & 16 & $1-58$ \\
\hline
\end{tabular}

1 Two modalities in 29 patients and 3 modalities in 3 patients.

random revealed that $71 \%$ were genotype $\mathrm{D}, 21 \%$ genotype $\mathrm{A}$ and $8 \%$ were genotype C. However, the genotypic distribution among patients with HCC was similar to the genotypic distribution among other patients with $\mathrm{HBV}$-induced chronic liver disease reported from our center and from other centers in this country [18, 19].

\section{Comparison of HCC Based on Etiology}

When comparing age, various biochemical variables and tumor characteristics based on various etiologies of HCC, only the mean age of HBV-related HCC was significantly lower than the HCV- and alcohol-related HCC $(49.3 \pm 11.8$ years vs. $59.6 \pm 11.3$ vs. $56.1 \pm 13.8, \mathrm{p}<$ $0.05)$. The mean bilirubin, albumin, aspartate transaminase and alanine transaminase levels did not reveal any significant difference. Serum AFP, tumor size and portal vein thrombosis also did not show statistical significance among the 3 major groups.

\section{Tumor Characteristics}

In 265 (85\%) patients, the dominant lesion was more than $3 \mathrm{~cm}$ in size (table 4). There was a single lesion in 215 (69\%) and $>5$ lesions in 35 (11\%). Portal vein involvement was identified on imaging in 129 (40\%). Extra-hepatic metastasis to peri-pancreatic nodes, celiac nodes, inferior vena cava thrombosis and lungs were seen in 41 (13\%) of the patients. The median serum AFP value in the $271 \mathrm{pa}-$ tients in whom it was available was $350 \mathrm{ng} / \mathrm{ml}$ (range $0.72-2,771,360 \mathrm{ng} / \mathrm{ml}$ ). The majority of the patients were in BCLC stage B and higher. Only 60 (20\%) were in stage $A$, in which surgery could be considered. Another 51 
Table 6. Cox regression analysis of various factors predicting survival

\begin{tabular}{|c|c|c|c|}
\hline & $\begin{array}{l}\text { Hazard } \\
\text { ratio }\end{array}$ & $\mathrm{p}$ value & $95 \% \mathrm{CI}$ \\
\hline Female & 0.77 & 0.28 & $0.43-1.28$ \\
\hline \multicolumn{4}{|l|}{ Etiology } \\
\hline Unknown & 1.0 & - & - \\
\hline $\mathrm{HBV}$ & 0.84 & 0.46 & $0.54-1.33$ \\
\hline $\mathrm{HCV}$ & 0.88 & 0.70 & $0.46-1.68$ \\
\hline Alcohol & 1.97 & 0.07 & $0.95-4.10$ \\
\hline Other ${ }^{1}$ & 1.71 & 0.12 & $0.86-3.41$ \\
\hline Blood transfusion & 0.93 & 0.84 & $0.43-1.99$ \\
\hline Chronic hepatitis & 1.10 & 0.43 & $0.71-1.70$ \\
\hline Cirrhosis & 1.03 & 0.87 & $0.72-1.47$ \\
\hline \multicolumn{4}{|l|}{ Child's score } \\
\hline $\mathrm{A}$ & 1.00 & & \\
\hline B & 1.98 & $<0.001$ & $1.35-2.90$ \\
\hline $\mathrm{C}$ & 2.36 & $<0.01$ & $1.30-4.30$ \\
\hline \multicolumn{4}{|l|}{ Diameter, $\mathrm{cm}$} \\
\hline$<2$ & 1.0 & - & - \\
\hline$>2$ & 1.55 & 0.05 & $0.99-2.41$ \\
\hline \multicolumn{4}{|l|}{ Number of lesions } \\
\hline 1 & 1.0 & - & - \\
\hline$>1$ & 0.99 & 0.96 & $0.68-1.45$ \\
\hline Distant metastases & 1.66 & 0.04 & $1.04-2.65$ \\
\hline Vascular involvement & 2.12 & $<0.001$ & $1.44-3.10$ \\
\hline \multicolumn{4}{|l|}{ Okuda staging } \\
\hline 1 & 1.0 & - & - \\
\hline 2 & 3.08 & $<0.001$ & $2.00-4.75$ \\
\hline 3 & 4.67 & $<0.001$ & $2.56-8.50$ \\
\hline Any treatment & 0.47 & $<0.001$ & $0.33-0.69$ \\
\hline
\end{tabular}

${ }^{1} \mathrm{HBV}+\mathrm{HCV}, \mathrm{HBV}+\mathrm{HCV}+$ alcohol and HBV + alcohol.

(17.5\%) of the patients were in stage $\mathrm{D}$, where curative or palliative therapy could be offered.

\section{Therapy and Outcome}

Out of the 324 patients included, 50 were in group I while 274 were in group II. BCLC staging could be performed in 292 patients, and BCLC stage A, B, C and D was seen in 15, 35, 23 and $28 \%$, respectively, in group I and $21,35,28$ and $16 \%$ in group II. Therapy could be offered to a total of $141(43.5 \%)$ patients [12 (24\%) of group I and $129(47 \%)$ of group II, p < 0.01]. The remaining 183 patients could not be offered any therapy due to factors such as advanced disease, non-affordability or refusal of treatment.

Survival data was available for 130 treated patients and 143 non-treated patients. Table 5 provides the details of therapy and the survival outcome.

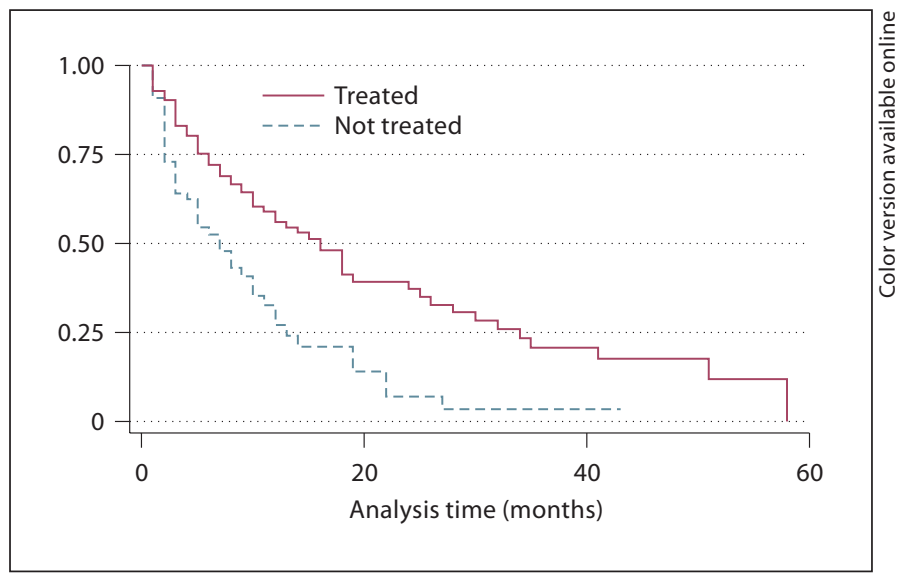

Fig. 5. Kaplan-Meier analysis of patients in relation to treatment. Broken line $=$ patients who did not receive treatment $(n=143)$; continuous line $=$ patients who received treatment $(n=130$; $\mathrm{p}=0.0000$, log-rank test).

Surgical resection was done in 14 patients (10.7\%) with a median survival of 19 months. Percutaneous therapy was given to 21 patients (PAI in 17 and RFA in 4 patients, mean sessions 3.8 and 1 , respectively), and the median survival was 13 and 24 months, respectively. TACE was offered to 23 patients (39 sessions) with a median survival of 11 months. TART $(n=7)$ and oral chemotherapy patients $(n=34)$ had a median survival of 26 and 5 months, respectively. Combined treatment $[\mathrm{n}=32$ (24.6\%)] patients had a survival of 26 months.

Follow-up data were available in 273 patients, out of which 124 died while 149 survived. The mean follow-up was $7.4 \pm 10.3$ months (median 3 months). The median survival for all patients using Kaplan-Meier estimates was 11 months. The median survival for the treated and untreated group was 16 and 7 months, respectively $(\mathrm{p}<$ 0.001; fig. 5). Other individual variables, which showed significant survival on Kaplan-Meier estimates, were portal vein invasion, Child's class, BCLC, Cancer of the Liver Italian Program (CLIP) and Okuda staging. The Kaplan-Meier estimate for median survival in the absence of portal vein invasion was 15 months and in patients with invasion it was 6 months $(\mathrm{p}=0.0007)$. When all the 3 major staging systems - BCLC, CLIP and Oku$\mathrm{da}$ - were put in a Cox's model in a stepwise manner, Okuda staging emerged as an independent predictor of survival. Child's score significantly correlated with survival: while it was 16 months in Child's A, it was only 6 months in Child's B and C ( $p=0.0002)$. 
There was no difference in survival in patients based on gender $(\mathrm{p}=0.28)$ or serum AFP level $(\mathrm{p}=0.60)$. Patients with alcohol-related HCC had poor survival when compared to viral causes of HCC, although this did not reach statistical significance $(\mathrm{p}=0.07)$. On Cox's regression analysis, vascular invasion, distant metastasis, Child's class, diameter of tumor and Okuda staging were factors that were associated with survival. Age, sex, past history of chronic hepatitis, AFP or number of lesions did not predict survival (table 6).

\section{Discussion}

This comprehensive study of HCC from the Indian subcontinent is the first of its kind to provide the clinical features, etiology, tumor characteristics, underlying risk factors and the outcomes of various therapies over a relatively long period of time in a developing country with intermediate endemicity for HCC.

Almost all our patients (97.5\%) had underlying cirrhosis, and infection due to HBV (59\%) emerged as the single most factor associated with HCC. This is consistent with other studies from the Indian subcontinent [20-22]. The carrier rate of $\mathrm{HBV}$ reported from India is 2-4\% [23]. Approximately 40 million HBV carriers exist in India, comprising $10 \%$ of the global burden.

HCV infection was seen in 48 (15\%) patients. In India, the prevalence of HCV is about $0.8-1.5 \%$ of the general population and it has been implicated as the causative agent in $14-26 \%$ of chronic liver disease in India $[24,25]$. In $13.4 \%$ of our patients, alcohol has been found as either the sole etiologic agent or in combination with viral hepatitis. Thus, HBV is a much more important carcinogen in Indian patients than in the West, where alcohol and $\mathrm{HCV}$ are the leading etiological agents.

The mean age of the patients in our study was 52.4 years which is similar to an earlier series from India [20]. HBV-related HCC patients in our study presented a decade earlier when compared to HCV-infected HCC patients ( 49.3 vs. 59.6 years), which is comparable with earlier studies [26, 27]. The younger age of HCC patients with HBV infection can be explained by 2 facts. First, the $\mathrm{HBV}$ carrier pool in India usually reaches a plateau by the age of 5 years $[28,29]$. In the general population, it is estimated that about $75 \%$ carriers would have acquired infection by horizontal spread during early childhood and about $25 \%$ by vertical transmission [30]. Second, HBV is a more potent oncogenic stimulus and can cause HCC without cirrhosis [31].

Hepatocellular Carcinoma in India
The majority of the HCC patients reporting to our hospital were in BCLC stages B and C [101 (34.6\%) and 80 (27.4\%), respectively] and about $89.5 \%$ of these were symptomatic at their first presentation, suggesting advanced disease to begin with. On account of this, only $141 / 324$ patients $(43.5 \%)$ could be offered treatment. This observation is quite consistent with other reports from the country $[20,22,32]$.

The major complaint of our patients with HCC was abdominal pain, which was seen in more than $50 \%$. Our earlier study has highlighted the importance of symptomatology (weight loss, anorexia and abdominal pain) as markers for HCC [33]. The strong male predominance in our study (the male to female ratio was 9:1) is similar to the global trend [34].

Serum AFP level $>400 \mathrm{ng} / \mathrm{ml}$ is taken as a conventional diagnostic level for HCC [35]. In this study, AFP was elevated in $71 \%$ of patients, but was above the diagnostic range in only $36 \%$ of patients. Low serum levels may be either because of smaller tumors or due to better differentiation of masses that do not produce high AFP [36]. The level of AFP did not show any correlation to the number of tumors or to the etiology of HCC.

An important aspect of the present study was that over a period of time and with the screening program available at our center, more treatable cases were picked up in group II patients as compared to group I [12 (24\%) in group I vs. 129 (47\%) in group II, p < 0.01]. Moreover, patients who underwent therapy at any stage had longer survival compared to untreated patients. On subgroup analysis, this was significant in early tumor stages (BCLC $\mathrm{A}$ and $\mathrm{B})$.

Only $14(10.7 \%)$ patients in the present series underwent hepatectomy and none underwent liver transplantation. In India, living donor liver transplantation is still at the nascent stage, with services limited to only 2 centers in the country and hence virtually nonexistent. Cadaveric liver transplantation is limited by shortage of donors and prolonged waiting periods. Additionally, the procedure is very expensive and, with no health insurance facilities available and severe economic constraints, it is virtually out of reach for the majority of the patients in India. However, cadaveric liver transplant has been available at our center for 6 months. Additionally, since most of our patients were in BCLC stages $B$ and $C$, this precluded surgical therapies. The overall median survival in our patient group was only 16 months and the untreated patients had a median survival of 7 months. This poor survival is similar to that reported in other studies $[37,38]$ and is attributed to the presence of advanced disease at the outset. 
Local ablative therapies with their minimal invasiveness form a very important curative treatment modality and are best for small unresectable HCC. While most studies have limited local therapies to tumors $<3 \mathrm{~cm}$, we offered these treatments to patients with tumors $\leq 5 \mathrm{~cm}$ and $\leq 5$ in number. In a randomized control trial, although RFA has been shown to be superior to PAI and percutaneous ethanol injection in local recurrence and overall survival, it caused significantly more complications [39]. PAI on the other hand is inexpensive, easy to use and has a better patient tolerance and safety profile, but requires multiple sessions for tumor necrosis. The mean number of sessions in our study for PAI and RFA were 3.8 and 1, respectively. Lin et al. [39] have shown that RFA required significantly fewer sessions as compared to percutaneous ethanol injection and PAI for complete tumor necrosis [37].

Transarterial therapies like chemoembolization (TACE), radionuclide therapy (TART), and chemotherapy (TAC) have been shown to improve the survival of patients with unresectable multifocal HCC with good residual liver function $[40,41]$. TART using rhenium $\left({ }^{188} \mathrm{Re}\right)$ was used in 7 patients with unresectable HCC with a median survival of 26 months. The median survival for patients who received TACE was 11 months. In one of the largest experiences of TACE, in 8,510 patients with HCC, the median survival was reported to be 34 months and the 1-, 3- and 5-year survival was 82,47 and $26 \%$, respectively [42].

Combined interventional treatments like TACE and PAI, RFA followed by TACE or TART and vice versa were used in our patients when use of one modality did not effectively control the disease and the disease progressed [43]. Combined therapy has been shown to benefit and prolong survival in patients with advanced tumors [43]. More than a third of our patients had portal vein involvement (40\%), in whom chemoembolization was contraindicated. This limited our therapeutic armamentarium and our ability to increase the survival of these patients to a significant extent.

Though there is no standard therapy for patients with advanced tumors who are not considered for any locoregional treatments, we used various systemic chemotherapeutic regimens, such as 5 -fluorouracil, long-acting octreotide, thalidomide and capecitabine in our patients. Combination of thalidomide and capecitabine was used in advanced HCC in 33 patients in our study. Although developed in the 1950s and later withdrawn, thalidomide is an anti-angiogenic drug and this effect is species specific. Given alone, thalidomide has moderate efficacy, has been shown to be useful in some patients with advanced HCC and it produces durable stability of disease in approximately one third of patients, with a partial response rate not beyond $10 \%[44,45]$. A preliminary study has suggested that sorafenib, an oral multikinase inhibitor of the vascular endothelial growth factor receptor, the platelet-derived growth factor receptor, and Raf, may be effective in HCC. When used in advanced HCC, median survival and the time to radiologic progression was nearly 3 months longer for patients treated with sorafenib than for those given a placebo [46]. Our patients were too poor to afford sorafenib. Even treatment with cheaper chemotherapeutic drugs used in this study was extremely difficult for them to afford.

When BCLC, CLIP and Okuda were put in a Cox's model in a stepwise manner, Okuda staging emerged as an independent predictor of survival in our patients. None of these staging systems are perfect and these models cannot provide a precise prognosis for individual patients. BCLC staging, however, provides a useful and logical guide for therapy according to the prognostic class.

In conclusion, $\mathrm{HBV}$ is the most common cause of HCC in India followed by HCV infection. Prevention of these etiologic agents is the only realistic means of reducing the morbidity and mortality of HCC. The survival of these patients can be improved by aggressively treating HCC, complications of cirrhosis and by controlling etiological factors. Serum AFP is not a very sensitive marker for diagnosis or surveillance and there is an urgent need for better markers and imaging to diagnose smaller tumors. Presence of vascular invasion, Okuda staging and treatment were found to be independently associated with survival.

\section{Acknowledgment}

The study was partly funded by the Indian Council of Medical Research, New Delhi, India, for the Advanced Centre of Liver Diseases. Sanction No. 5/8/7/26/99-ECD-1.

References

1 Parkin DM, Bray F, Ferlay J, et al: Estimating the world cancer burden: GLOBOCAN 2000. Int J Cancer 2001;94:153-156.

2 Bosch FX, Ribes J, Borras J: Epidemiology of primary liver cancer. Semin Liver Dis 1999; 19:271-285.

3 Pisani P, Parkin DM, Ferlay J: Estimates of the world wide mortality from eighteen major cancers in 1985: implications for prevention and projections of future burden. Int J Cancer 1993;55:891-893. 
4 Bruix J, Sherman M, Llovet JM, et al: EASL panel of experts on HCC. Clinical management of hepatocellular carcinoma: conclusions of the Barcelona 2000 EASL conference. European Association for the Study of Liver. J Hepatol 2001;35:421-430.

$\checkmark 5$ Yoshizawa H: Hepatocellular carcinoma associated with hepatitis $\mathrm{C}$ virus infection in Japan: projection to other countries in the foreseeable future. Oncology 2002;62(suppl 1):8-17.

6 Acharya SK, Madan K, Datta Gupta S, Panga SK: Viral hepatitis in India. Natl Med J India 2006;19:203-217.

-7 Kumar M, Kumar R, Hissar SS, et al: Risk factors analysis for hepatocellular carcinoma in patients with and without cirrhosis: a case-control study of 213 hepatocellular carcinoma patients from India. J Gastroenterol Hepatol 2007;22:1104-1111.

$>8$ Chowdhury A, Santra A, Chaudhuri S, et al: Hepatitis $C$ virus infection in the general population: a community-based study in West Bengal, India. Hepatology 2003;37: 802-809.

-9 Prabhakar V, Rao KS, Reddy DJ: Primary carcinoma of liver in Visakhapatnam. Indian J Pathol Microbiol 1966;9:54-60.

10 Paul SB, Sreenivas V, Gulati MS, et al: Incidence of hepatocellular carcinoma among Indian patients with cirrhosis of liver: an experience from a tertiary care center in northern India. Indian J Gastroenterol 2007;26: 274-278.

-11 Kumar Acharya S, Kumar Sharma P, Singh $\mathrm{R}$, et al: Hepatitis E virus (HEV) infection in patients with cirrhosis is associated with rapid decompensation and death. J Hepatol 2007;46:387-394

-12 Panigrahi AK, Panda SK, Dixit RK, et al: Magnitude of hepatitis $C$ virus infection in India: prevalence in healthy blood donors, acute and chronic liver diseases. J Med Virol 1997;51:167-174.

13 Panigrahi AK, Roca J, Acharya SK, Jameel S, Panda SK: Genotype determination of hepatitis $\mathrm{C}$ virus from northern India: identification of a new subtype. J Med Virol 1996;48: 191-198.

-14 Chaudhuri V, Tayal R, Nayak B, Acharya SK, Panda SK: Occult hepatitis B virus infection in chronic liver disease: full-length genome and analysis of mutant surface promoter. Gastroenterology 2004;127:1356-1371.

$\checkmark 15$ Hazari S, Acharya SK, Panda SK: Development and evaluation of a quantitative competitive reverse transcription polymerase chain reaction (RT-PCR) for hepatitis C virus RNA in serum using transcribed thioRNA as internal control. J Virol Methods 2004;116:45-54.

-16 Pugh RN, Murray M, Dawson MC, et al: Transection of esophagus for bleeding esophageal varices. Br J Surg 1973;60:646648
17 Llovet JM, Bru C, Bruix J: Prognosis of hepatocellular carcinoma: the BCLC staging classification. Semin Liv Dis 1999;19:329-338.

18 Thakur V, Guptan RC, Kazim SN, Malhotra V, Sarin SK: Profile, spectrum and significance of HBV genotypes in chronic liver disease patients in the Indian subcontinent. J Gastroenterol Hepatol 2002;17:165-170.

19 Tanaka Y, Hasegawa I, Kato T, et al: A case control study for difference among hepatitis $B$ virus infections of genotype A (subtype Aa and Ae) and D. Hepatology 2004;40:747755.

20 Sarin SK, Thakur V, Guptan RK, et al: Profile of hepatocellular carcinoma in India: an insight into the possible etiologic associations. J Gastroenterol Hepatol 2001;16:666-673.

21 Murugavel KG, Mohan KVK, Pramod NP, et al: Correlation of hepatitis $\mathrm{B}$ and $\mathrm{C}$ viral markers with aflatoxin and AFP in hepatocellular carcinoma cases from Tamil Nadu. Abstract. Indian J Gastroenterol 1999;18: S37.

22 Kapoor S, Gupta SK, Dhiman RK, et al: Hepatocellular carcinoma at PGI Chandigarh. Indian J Gastroenterol 1999;18:S36.24

-23 Tandon BN, Acharya SK, Tandon A: Epidemiology of hepatitis B virus infection in India. Gut 1996;38:856-859.

24 Ramesh R, Munshi A, Panda SK: Prevalence of hepatitis $\mathrm{C}$ virus antibodies in chronic liver disease and hepatocellular carcinoma patients in India. J Gastroenterol Hepatol 1992; 7:393-395.

25 Panigrahi AK, Panda SK, Dixit RK, et al: Magnitude of hepatitis $C$ virus infection in India: prevalence in healthy donors, acute and chronic liver disease. J Med Virol 1997; 51:167-174.

26 Stroffolini T, Andreone P, Andriulli A, et al: Characteristics of hepatocellular carcinoma in Italy. J Hepatol 1998;29:944-952.

27 Shiratori Y, Shiina S, Imamura M, et al: Characteristic difference of hepatocellular carcinoma between hepatitis B- and C-viral infection in Japan. Hepatology 1995;22: 1027-1033

28 Tandon BN, Irshad M, Raju M, Mathur GP Rao MN: Prevalence of HbsAg and anti$\mathrm{HBC}$ in children and strategy suggested for immunization in India. Indian J Med Res 1991;93:337-339.

29 Sobeslavsky O: Prevalence of markers of hepatitis B virus infection in various countries: a WHO collaborative study. Bull WHO 1980;58:621-628.

30 Aggarwal R, Naik SR: Prevention of hepatitis B infection: the appropriate strategy for India. Natl Med J India 1994;7:216-220.

31 International Agency for Research on Cancer: Monographs on the Evolution of Carcinogenic Risks to Humans: Hepatitis Viruses, vol 59. Geneva, World Health Organisation, 1994.

-32 Kumar R, Saraswat MK, Sharma BC, Sakhuja P, Sarin SK: Characteristics of HCC in India. QJM 2008;101:479-485.
33 Paul SB, Gulati MS, Sreenivas V, et al: Evaluating patients with cirrhosis for hepatocellular carcinoma: value of clinical symptomatology, imaging and alpha-fetoprotein. Oncology 2007;72(suppl 1):117-123.

34 Fattovich G, Stroffoloni T, Zagni I, et al: Hepatocellular carcinoma in cirrhosis: incidence and risk factors. Gastroenterology 2004; 127:S35-S50.

35 Daniele B, Bencivenga A, Megna AS, Tinessa $\mathrm{V}$ : Alpha fetoprotein and ultrasonography screening for hepatocelluar carcinoma. Gastroenterology 2004;127:S108-S112.

36 Watanabe A, Yamamoto H, Ito T, et al: Diagnosis, treatment and prognosis of small hepatocellular carcinoma. Hepatogastroenterlogy 1986;33:52.

37 Sangro B, Herraiz M, Martinez-Gonzalez MA, et al: Prognosis of hepatocellular carcinoma in relation to treatment: a multivariate analysis of 178 patients from a single European institution. Surgery 1998;124:575-583. Erratum in: Surgery 1998;124:1087.

38 Schoniger-Hekele M, Muller C, Kutilek M, et al: Hepatocellular carcinoma in Austria: aetiological and clinical characteristics at presentation. Eur J Gastroenterol Hepatol 2000; 12:941-948.

>39 Lin SM, Lin CJ, Lin CC, Hsu CW, Chen YC: Randomised controlled trial comparing percutaneous radiofrequency thermal ablation, percutaneous ethanol injection, and percutaneous acetic acid injection to treat hepatocellular carcinoma of $3 \mathrm{~cm}$ or less. Gut 2005; 54:1151-1156.

40 Llovet JM, Bruix J: Systematic review of randomized trials for unresectable hepatocellular carcinoma: chemoembolization improves survival. Hepatology 2003;37:429-442.

-41 Lo CM, Ngan H, Tso WK, et al: Randomized controlled trial of transarterial lipiodol chemoembolization for unresectable hepatocellular carcinoma. Hepatology 2002;35:11641171.

42 Takayasu K, Arii S, Ikai I, et al; Liver Cancer Study Group of Japan: Prospective cohort study of transarterial chemoembolization for unresectable hepatocellular carcinoma in 8,510 patients. Gastroenterology 2006;131: 461-469.

43 Liu YM, Qin H, Wang CB, Fang XH, Ma QY: Comparison of therapeutic effectiveness of combined interventional therapy for 1,126 cases of primary liver cancer. World J Gastroenterol 2006;12:5060-5063.

$\checkmark 44$ Wang TE, Kao CR, Lin SC, et al: Salvage therapy for hepatocellular carcinoma with thalidomide. World J Gastroenterol 2004;10: 649-653

45 Lin AY, Brophy N, Fisher GA, et al: Phase II study of thalidomide in patients with unresectable hepatocellular carcinoma. Cancer 2005;103:119-125.

46 Llovet JM, Ricci S, Mazzaferro V, et al: Sorafenib in advanced hepatocellular carcinoma. N Engl J Med 2008;359:378-390. 